\title{
National Trauma System Establishment Based on Implementation of Regional Trauma Centers Improves Outcomes of Trauma Care; A Follow-up Observational Study in South Korea
}

\section{Kyoungwon Jung}

Ajou University School of Medicine and Graduate School of Medicine https://orcid.org/0000-00017895-0362

Junsik Kwon

Ajou University School of Medicine and Graduate School of Medicine Yo Huh

Ajou University School of Medicine and Graduate School of Medicine Jonghwan Moon

Ajou University School of Medicine and Graduate School of Medicine Kyungjin Hwang Ajou University School of Medicine and Graduate School of Medicine Hyun Min Cho Jeju Halla Byeongwon: Cheju Halla General Hospital

Jae Hun Kim

Pusan National University College of Medicine: Pusan National University School of Medicine Chan Ik Park

Pusan National University College of Medicine: Pusan National University School of Medicine Jung-Ho Yun

Dankook University College of Medicine

Oh Hyun Kim

Yonsei University Wonju College of Medicine

Kee-Jae Lee

Korea National Open University

Sunworl Kim

National Medical Center

Borami Lim

National Medical Center

Yoon Kim ( $\nabla$ yoonkim@snu.ac.kr)

Seoul National University College of Medicine 
Research article

Keywords: trauma systems, trauma centers, preventable deaths, outcomes, quality improvement

Posted Date: April 5th, 2021

DOl: https://doi.org/10.21203/rs.3.rs-372078/v1

License: (c) (i) This work is licensed under a Creative Commons Attribution 4.0 International License. Read Full License

Version of Record: A version of this preprint was published at PLOS Global Public Health on January 13th, 2022. See the published version at https://doi.org/10.1371/journal.pgph.0000162. 


\section{Abstract}

Background: Although Korea is a high-income country, its trauma system is comparable to low- and middle-income countries with high preventable trauma death rates (> 30\%). Since 2012, Korea has established a national trauma system based on the implementation of regional trauma centers and improvement of the transfer system; this study aimed to evaluate its effectiveness.

Methods: We compared the national preventable trauma death rates, transfer patterns, and outcomes between 2015 and 2017. The review of preventable trauma deaths was conducted by multiple panels and a severity-adjusted logistic regression model was created to identify factors influencing the preventable trauma death rate. We also compared the number of trauma patients transferred to emergency medical institutions and mortality in models adjusted with injury severity scores.

Results: The preventable trauma death rate decreased from 2015 to 2017 (30.5\% vs. 19.9\%, p<0.001). In the severity-adjusted model, the preventable trauma death risk had a lower odds ratio $(0.68,95 \%$ confidence interval: $0.53-0.87, p=0.002)$ in 2017 than in 2015. Regional trauma centers received 1.6 times more severe cases in 2017 (according to the International Classification of Diseases Injury Severity Score [ICISS]; $23.1 \%$ vs. $36.5 \%)$. In the extended ICISS model, the overall trauma mortality decreased significantly from $2.1 \%(1008 / 47806)$ to $1.9 \%(1062 / 55057)(p=0.041)$.

Conclusions: Establishment of the national trauma system was associated with significant improvements in performance and outcomes of trauma care. This was mainly because of the implementation of regional trauma centers and because more severe patients were transferred to regional trauma centers. This study might be a good model for low- and middle-income countries, which lack a trauma system.

\section{Background}

Injury, the leading cause of death in reproductive-age group individuals $<40$ years, is a major public health problem [1-3]. Each year, $10 \%$ of people die from injury, and many more are disabled $[3,4]$. Although the magnitude of the burden of injury is alarming when compared with that of other diseases [3], the interest and investment are less than those for other public health issues [5]. The burden is especially high in low- and middle-income countries (LMICs) because more than $90 \%$ of injury-related deaths occur in LMICs [6]. Remarkable reductions in injury-related mortality, disability, and costs have been achieved in many healthcare jurisdictions with the introduction of trauma systems [7-12]; however, well-organized trauma systems have only been minimally implemented in most LMICs [4].

A trauma system can be broadly defined as an organized, regional, multidisciplinary approach to trauma care, although there are various definitions [13, 14]. Moreover, the World Health Organization (WHO) and the American College of Surgeons provided consensus-based recommendations on the structure of trauma systems [4, 14-16]. Many studies have evaluated the effectiveness of trauma systems; nonetheless, it is challenging that these studies have provided low quality evidence [17]. Although the 
majority of the abovementioned studies covered an inclusive design of trauma systems, they mainly targeted outcomes for specific cohort populations or organ injury on a statewide level. Few studies have been conducted to follow up, serially and prospectively, the effect of a national trauma system (NTS) for all emergency medical institutions (EMIs) across the country.

Although South Korea is a high-income country, its trauma system has not reached that level. Despite trauma being one of the three major causes of death in South Korea, alongside cancer and cardiovascular diseases, and one of the four major causes of death in the emergency department (ED) [2, 18], the preventable trauma death rate (PTDR) was high enough to exceed $30 \%$ by the 2010 s, which was similar to that in LMICs [19-21]. Although a multidisciplinary approach for the systematic establishment of trauma systems is required to reduce the PTDR, there has been less interest or investment in the trauma field than in fields of infectious issues, oncology, and chronic disease in South Korea [22]. To improve these circumstances, the South Korean government implemented a NTS in 2012 that was geared towards the implementation of regional trauma centers (RTCs) nationwide and improvement in the prehospital transfer system.

We planned a national follow-up survey every 2 years since the implementation of the NTS to confirm its effectiveness. First, a survey of PTDR based on multi-panel review was designed because the primary goal of the NTS establishment was PTDR reduction in South Korea. In addition, nationwide emergency medical data were analyzed to identify changes in performance and outcomes of national trauma care. In this study, we hypothesized that following the introduction of the trauma system, patients with severe trauma would be more concentrated in RTCs, and therefore, treatment outcomes would improve nationwide.

\section{Methods}

\section{Explanation of the emergency medical system in South Korea}

The promulgation of the Emergency Medical Service Act in 1994 became the starting point for the establishment of the modern emergency medical system in South Korea; the current system was established in the 2000s [23]. This is more than 30 years behind the United States of America (USA) and Western European countries, where separate organizations for the management of emergency patients have operated with national support since the 1960s. The system was created by rating three levels of EMIs according to the level of available resources or specialized care. These EMIs included the Regional Emergency Medical Center (REMC), Local Emergency Medical Center (LEMC), and the Local Emergency Medical Institution (LEMI). The REMC and LEMI represent the highest and lowest levels of EMIs, respectively. The LEMCs are also subdivided into tertiary hospitals with $\geq 500$ beds and general hospitals with 300-499 as well as $<300$ beds. In 2017, there were 36 REMCs, 118 LEMCs, and 261 LEMIs, and the funding received by EMls amounted to 250 million United States dollars (USD) [18].

\section{Master plan for the establishment of a national trauma system in South Korea}


The South Korean government and the medical society created a master plan for NTS establishment in 2012 (Figure 1a) [24]. The law on the establishment and operation of RTCs was enacted in the Emergency Medical Service Act and candidate institutions for RTCs, among REMCs and LEMC with $\geq$ 500 beds that met the criteria, were publicly recruited and selected after evaluation. Essentially, each institution would be equipped with facilities and equipment dedicated to the management of trauma patients, including $\geq 2$ resuscitation rooms, $\geq 1$ operating room always available for emergency surgery, an intensive care unit (ICU) with $\geq 20$ beds, and a general ward with $\geq 40$ beds. The South Korean government provided 67 million USD per institution for the construction these facilities and equipment and also supported labor cost for 25 dedicated trauma doctors per institution since designation. By 2017, 16 RTCs were designated and 9 RTCs were officially opened (Figure 1b) [18, 24].

\section{Database used for the study}

We used data from the National Emergency Department Information System (NEDIS), which collected healthcare-related information registered by EMls nationwide in real time based on the Emergency Medical Service Act. In 2017, 413 of 416 EMIs nationwide transmitted data, and the total number of transmissions was approximately 9,100,000 (See Additional file 1). The Korean Trauma Data Bank (KTDB) was established in 2013 to prepare the base for the trauma system by collecting information transmitted from RTCs. The KTDB has injury severity scores registered by full-time trauma coordinators. In 2017, 14 institutions registered information for 2,000-3,000 trauma admissions per RTC.

\section{National survey of the preventable trauma death rate by multi-panel review}

We performed a national survey on PTDR every 2 years beginning from 2015. The investigation was conducted in the following order: design/extraction of the sample population, data collection, panel review, reliability test for the review process, and result analysis. The criteria and review process for the decision on preventability were mainly based on the WHO guidelines for trauma quality improvement programs [4].

The target population for sampling was selected from trauma deaths with at least one diagnostic codes of $\mathrm{S}, \mathrm{T}$ based on the Korean Standard Classification of Diseases (the Korean version of the International Classification of Disease) of 2015 and 2017 according to the NEDIS (Figure 2a). After obtaining approval (E-1811-005-982) from the Institutional Review Board of Seoul National University Hospital, data were collected. All medical records, including imaging studies, were obtained from the EMIs with cooperation from the central and local governments, in accordance with the Medical Service Act. Pre-hospital information including the data of hospitals that transferred patients were also included.

We used a structured review form, including audit filters, for the review of medical records (see Additional file 2). The review form was based on the data sheet for use in preventable death panel reviews with embedded audit filters as in the WHO guidelines for the Trauma Quality Improvement Program (TQIP). Designated assistants (pre-reviewers), comprising trauma coordinators (overall, 5 in 2015 and 12 in 2017) working in RTCs nationwide, investigated and recorded the general characteristics of patients, 
injury-related information, as well as transport and treatment-related information, using the review form before the preventable death panel review. The case review panels mainly comprised trauma specialists working at RTCs. A total of 10 teams in 2015 and five teams in 2017 were formed, and each team consisted of two general surgeons, one thoracic surgeon, one neurosurgeon, and one emergency physician. Moreover, a committee that comprised five trauma specialties, was responsible for developing guidelines for the entire review process and for training reviewers. When preventability was not decided by the multi-panel review, the committee reviewed and confirmed the final decisions. Three teams were selected to evaluate the reliability of the panel review. They repeated reviews for $5 \%$ of the overall cases that had already been reviewed by other teams (see Additional file 3).

\section{National evaluation of the performance and outcomes of the new trauma system}

An analysis was conducted to compare the performances and outcomes of trauma care between two survey periods. International Classification of Disease Injury Severity Score (ICISS), extended ICISS, and Trauma and Injury Severity Score (TRISS) models were created for severity adjustments. We calculated the probability of survival (Ps) from these models for the outcome analysis (Figure 2b). The extended ICISS indicated an ICISS model adjusted for age and the Revised Trauma Score (RTS). To calculate the RTS, the initial physiologic parameters on ED admission were used. The LEMIs were excluded from the extended ICISS model because physiologic parameters in LEMIs were not registered to NEDIS. Since the injury severity scores required for the TRISS model are only registered in the KTDB, it was possible to create TRISS only with data collected from RTCs.

\section{Statistical analysis}

To calculate the nation's representative PTDR and improve the efficiency of the panel review, we selected the target of the trauma death review through stratified two-stage cluster sampling. The stratification was designed as a double layer (see Additional file 4); the primary stratified variables were region and EMI level, and the secondary stratified variables were place (timing) of death and patient age. Our initial targeted sample sizes were 1,000 in 2015 and 1,300 in 2017; however, considering the cases to be excluded from the panel review, the survey sample sizes were determined to be 1,131 and 1,862, respectively (see Additional file 5). The sample size was targeted such that stable estimation would be possible to meet a limit of error of approximately $\pm 4.5 \% p$ (2015) and $\pm 3.8 \% p$ (2017) at $95 \%$ confidence levels for population ratio estimation.

To estimate the population PTDR, the sample weights of each hospital level and death were calculated according to the sample design method and applied to analyze the sample-designed survey data. For continuous data, normality testing was performed using the Kolmogorov-Smirnov test. Categorical variables were compared using the Chi-Square and Fisher's exact tests accordingly. Comparison between groups was performed using the t-test and analysis of variance. The paired t-test was used to compare differences in 2015 and 2017. To examine the association between the likelihood of preventable death and its relating factors, we constructed multivariate logistic regression models. The goodness of fit for the models was confirmed through the Hosmer-Lemeshow test. The agreement between panel teams was 
evaluated using Cohen's Kappa index. All statistical analyses were performed using SPSS (Version 18.0; IBM Corp., Armonk, NY), and two-sided $p$ values $<0.05$ were considered to indicate statistical significance.

\section{Results}

\section{Change in the preventable trauma death rate and influencing factors}

Overall, trauma deaths comprised 6,988 deaths from 355 EMIs in 2015 and 8,282 deaths from 368 EMls in 2017 registered in the NEDIS. Of these, the number of sample cases included for the PTDR review was 975 (14.0\%) from 60 EMls in 2015 and 1,251 (15.1\%) from 117 EMls in 2017; the number of final weighted data for comparative analysis was 906 in 2015 and 1,232 in 2017. In the reliability test for the panel review, the Kappa index was 0.49 in 2015 and 0.61 in 2017, indicating moderate and substantial agreements, respectively.

The PTDR in 2017 was lower than that in 2015 (19.9\% vs. 30.5\%, $p<0.001)$ (Table 1, Figure 3a). The PTDR in the group after admission to the first hospital decreased significantly from 2015 to 2017 (37.1\% vs. $18.2 \%, p<0.001)$. In terms of regions, the PTDR significantly decreased in all regions except Region I, where there was a minimal change from 30.8\% in 2015 to 30.2\% in 2017 (Table 1, Figure 3b). Regarding EMIs that were the destinations of hospitalization, the LEMCs and LEMIs presented significantly lower PTDRs in 2017 (all $p<0.001$ ). The PTDR significantly decreased in the no transfer group from 2015 to $2017(28.4 \%$ vs. $15.5 \%, p<0.001)$.

In the most valid logistic regression model, ICISSs, RTSs, and Region IV were found to be factors that significantly influenced preventable death (Figure 4). In the severity-adjusted model, the risk of preventable death indicated a significantly lower odds ratio $(0.68,0.53-0.87)$ in 2017 than in 2015. Additionally, Region III had a significantly different odds ratio $(0.58,0.37-0.89)$ than Region I. Region III employed the greatest number of beds according to the population $\left(8.5\right.$ beds $\left./ 10^{6}\right)$ and the number of trauma ICU beds per the number of patients with severe trauma (7.6 beds/100) in 2017.

\section{Changes in the transfer patterns and outcomes of trauma patients}

According to the NEDIS, 1,790,165 and 1,914,731 patients with trauma in 2015 and 2017, respectively, visited EMls. Of these, 4,288 (0.24\%) in 2015 and 4,789 (0.25\%) in 2017 were severe trauma patients who had Ps $<0.5$ according to the ICISS model (Table 2). Based on the extended ICISS model, there were 3,306 (6.9\%) severe cases in 2015 and 3,891 (7.1\%) in 2017 with Ps $<0.75$ among trauma patients $(47,806$ in 2015 and 55,057 in 2017) who visited RTCs, REMCs, and LEMCs. In RTCs, 744 (17.5\%) severe trauma patients with Ps $<0.75$ in 2015 and 1,120 (18.6\%) in 2017 were treated based on the TRISS model. Distinguishing per the type of EMI, $11.3 \%$ of all trauma patients in 2015 visited an REMC or RTC; the percentage increased to $19.7 \%$ in 2017 (Figure 5a). Meanwhile, the number of ICISS-based severe trauma patients increased by $21.6 \%$ points (from $30.7 \%$ in 2015 to $52.3 \%$ in 2017 ) in REMCs and RTCs. In particular, the percentage of severe trauma patients received in RTCs in 2017 (36.5\%) was 1.6 times 
higher than that received in 2015 (23.1\%); thus, accounting for more than 1/3 of the total number of severe cases (Figure $5 b$ ).

Compared with that in 2015 , the severity-adjusted trauma mortality rate was lower in 2017 . In the extended ICISS model, the overall mortality decreased significantly from $2.1 \%(1,008 / 47,806)$ in 2015 to $1.9 \%(1,062 / 55,057)$ in $2017(p=0.041)$. The reduction rate was the greatest in severe cases with $\mathrm{Ps}<$ 0.25 from 2015 to 2017 , although insignificant ( $53.2 \%$ vs. $49.9 \%, p=0.079$ ) (Figure $5 c$ ). In the TRISS model, the overall mortality rate of severe trauma patients did not significantly change from 2015 to 2017 ( $4.7 \%$ to $4.4 \% ; p=0.455)$, and the mortality rate of cases with $\mathrm{Ps}<0.25$ decreased by $6.3 \%$, although insignificant ( $56.5 \%$ vs. $50.2 \%, p=0.091$ ) (Figure $5 \mathrm{~d}$ ).

\section{Discussion}

Although it is emphasized that the trauma system should be built as an inclusive design [7-12], it is not easy to do so on a national level. Furthermore, it is difficult to prove the effectiveness of trauma systems. Studies have evaluated the effectiveness of the NTS; however, most studies have provided low quality evidence [17]. The biggest problem has been adequately adjusting for referral bias. In this study, we adopted a different approach; the PTDR was estimated through multi-panel reviews since the purpose of this project was to lower the PTDR in South Korea; an analysis was performed on all trauma patients using the existing database.

Preventability judgments may be subjective, and there may be variations in reliability between different panel assessments; nonetheless, death panel reviews remain a straightforward method of accomplishing the goal of assessing and improving the quality of care [4]. Despite the lack of quantitative precision, these reviews are often a major stimulus for improvements in trauma care $[25,26]$. In this study, the definition of preventability and the review methodology essentially followed the WHO TQIP guidelines, and the results of reliability evaluations among team panels showing moderate to substantial agreement were comparable to those of previous studies [19-21, 27].

Here, we noted that the PTDR significantly decreased by $10 \%$ from 2015 to 2017, indicating that the national goal of $<20 \%$ decrease by 2020 has already been achieved. However, we realized that there were many factors that could be improved because the rate of definitively preventable deaths did not decrease when compared with that of potentially preventable deaths. One of the prominent points in the comparison of the PTDR was the differences among regions. There was no PTDR difference in Region I (Seoul), whereas the remaining four regions experienced a significant decrease, showing similar declines of $10 \%-15 \%$. This indicates that the trauma care system has not improved in Seoul, which was the only region where RTCs have not hitherto operated. In severity-adjusted models, Region III had a significantly lower odds ratio than Region I for PTDR, probably because Region III secured the greatest number of trauma ICU beds in the region.

The role of RTCs in decreasing the PTDR between 2015 and 2017 was not statistically remarkable. This may be owing to the limitations of the PTDR calculation method. A type of EMI, which was recorded as a 
final-destined hospital for trauma deaths, was not attributed solely to the responsibility of PTDR. Rather, we had to consider the injury severity and errors occurring at the pre-hospital or inter-hospital stage. In the severity-adjusted model, the RTCs tended to have lower odds ratio than other EMIs, although insignificant. Nevertheless, the effectiveness of the NTS establishment in South Korea is evident as the year 2017 had a lower odds ratio of PTDR at $68 \%$ than 2015.

The national trauma incidence increased by 125,000 cases in 2 years, and the number of severe cases with Ps $<50 \%$ increased by 500 . These trauma patients were commonly transferred to RTCs; this trend was more pronounced for severe cases (at least $50 \%$ were transferred to REMCs or RTCs and at least $33 \%$ to RTCs). The outcome of severity-adjusted trauma mortality was better in 2017 than in 2015. Severe trauma patients with lower Ps showed greater outcome improvements in EMls other than LEMIs; however, the number of cases was not enough to show a significant reduction in RTCs. Consequently, it is assumed that the transfer of severe cases to RTCs increased as a result of trauma system establishment; this would have contributed to outcome improvements.

There has been controversy regarding the appropriate number of trauma centers, even in the USA where an inclusive trauma system has been established for more than 50 years [28-32]. Although a different standard should be applied in South Korea, which has different injury mechanisms and a different geographical environment from the USA, 17 RTCs seem insufficient to cover trauma patients nationwide. Nevertheless, we believe that the implementation of these RTCs is the starting point for trauma outcome improvement. Establishing these RTCs would be the basis for building an inclusive NTS when integrating with other EMls. When enacting the law to establish trauma systems, the South Korean government announced its plan to extend the number and scale of RTCs, and included the designation of lower level trauma centers that would be considered for recruitment among REMC and LEMC with $>300$ beds. If the NTS is further established in this way, approximately $90 \%$ of severe trauma patients will be covered by the system.

This study has some limitations. First, the retrospective study design precluded the analysis of unrecorded factors or missing values. Second, the evaluation of preventability relied entirely on analysis by expert panels, which has limitations in objective reproducibility. Third, there were slight differences in sampling methods and panel reviews between 2015 and 2017. The number of EMls and cases targeted for sampling increased in 2017. The panels had to visit EMls to review medical records, and follow-up review was possible only for data recorded on the review forms in 2015, whereas all data from EMIs were reviewed in one place in 2017. Thus, repeated reviews were possible for all data in 2017. Hence, 10 teams were required for panel review in 2015 and only five teams in 2017. Fourth, the extended ICISS model could not be applied for LEMIs because LEMIs did not register initial ED physiologic parameters in the NEDIS. Fifth, the standards of Ps for severe cases in the severity-adjusted models ( $<0.5$ in the ICISS, $<0.25$ in the extended ICISS and TRISS) were arbitrary. They were decided by the authors considering that higher standards should be applied to higher level EMls. Finally, we replaced age group, transfer (yes/no), and place of death with continuous values of age, RTS, and ICISS when creating the logistic regression 
model. This was owing to the difficulty in obtaining a statistically valid model when the stratification variables used for sampling were applied to the logistic regression model.

\section{Conclusions}

The government-led establishment of the NTS (including financial investment) was associated with a significant improvement in the performance and outcomes of trauma care nationwide in South Korea. Trauma outcomes improved as RTCs became operational nationwide, and more severe cases were transferred to RTCs. Based on these results, we can expect a further decrease in the PTDR in South Korea when RTCs mature and more severe cases are concentrated at EMls with high levels of trauma care. The results of this study may provide a good model for LMICs currently lacking a trauma system.

\section{Abbreviations}

LMICs, low- and middle-income countries; WHO, World Health Organization; NTS, national trauma system; EMI, emergency medical institution; ED, emergency department; PTDR, preventable trauma death rate; RTC, regional trauma centers; USA, the United States of America; REMC, Regional Emergency Medical Center; LEMC, Local Emergency Medical Center; LEMI Local Emergency Medical Institution; USD, United States dollars; ICU, intensive care unit; NEDIS, National Emergency Department Information System; KTDB, Korean Trauma Data Bank; TQIP, Trauma Quality Improvement Program; ICISS, International Classification of Disease Injury Severity Score; TRISS, Trauma and Injury Severity Score; Ps, probability of survival; RTS, Revised Trauma Score.

\section{Declarations}

\section{Ethics approval and consent to participate}

This study was approved by the Institutional Review Board (IRB) of Seoul National University (IRB No. E1811-005-982). Informed consent was waived by the board due to the observational nature of the study.

\section{Consent for publication}

Not applicable.

\section{Availability of data and materials}

The datasets generated and/or analyzed during the current study are available from the corresponding author on reasonable request.

\section{Competing interests}

The authors declare that they have no competing interests. 


\section{Funding}

This study was funded by the Ministry of Health and Welfare, Republic of Korea. The funder of the study had no role in study design, data collection, data analysis, data interpretation, or writing of the report. All authors had full access to all the data in the study and had final responsibility for the decision to submit for publication.

\section{Authors' contributions}

All authors conceived the idea for the study. $\mathrm{KJ}$ and $\mathrm{YK}$ designed the study methodology. $\mathrm{KJ}, \mathrm{KH}, \mathrm{KJL}$, SK, $\mathrm{BL}$, and $\mathrm{YK}$ contributed to the acquisition of data. $\mathrm{KJ}, \mathrm{JK}, \mathrm{YH}, \mathrm{JM}, \mathrm{HMC}, \mathrm{JHK}, \mathrm{CIP}, \mathrm{JHY}$, and OHK did the investigation. $\mathrm{KJ}, \mathrm{KH}, \mathrm{KJL}, \mathrm{SK}, \mathrm{BL}$, and $\mathrm{YK}$ have verified the underlying data and contributed to data analysis. $\mathrm{KJ}, \mathrm{JK}, \mathrm{YH}, \mathrm{JM}, \mathrm{HMC}, \mathrm{JHK}, \mathrm{CIP}, \mathrm{JHY}, \mathrm{OHK}$, and $\mathrm{YK}$ contributed to the interpretation of data. $\mathrm{KJ}$, $\mathrm{KH}$, and SK contributed to the initial drafting of the manuscript. KJ and YK contributed to study supervision. All authors critically reviewed the manuscript and approved the final version.

\section{Acknowledgements}

This study was funded by the Ministry of Health and Welfare, Republic of Korea.

\section{References}

1. Key Injury and Violence Data. Available at: https://www.cdc.gov/injury/wisqars/overview/key_data.html. Centers for Disease Control and Prevention. Alanta, GA. Accessed December 1, 2020.

2. Leading Causes of Death Reports 1983-2019. Available at: https://kosis.kr/statisticsList/statisticsListIndex.do? menuld=M_01_01\&vwcd=MT_ZTITLE\&parmTabld=M_01_01\#SelectStatsBoxDiv. Korean Statistical Information Service. Seoul, Republic of Korea. Accessed December 1, 2020.

3. World Health Organization. The Global Burden of Disease: 2004 Update. Geneva: WHO Press; 2008.

4. World Health Organization. International Association for Trauma Surgery and Intensive Care, International Society of Surgery. Guidelines for trauma quality improvement programmes. Geneva: WHO Press; 2009.

5. World Health Organization. WHO Results Report - Programme Budget 2018-2019. Available at: https://www.who.int/about/accountability/results/2018-2019. WHO Press. Geneva, Switzerland. Accessed December 1, 2020.

6. Wesson HK, Boikhutso N, Bachani AM, Hofman KJ, Hyder AA. The cost of injury and trauma care in low- and middle-income countries: a review of economic evidence. Health Policy Plan. 2014 Sep;29(6):795-808.

7. Moore L, Evans D, Hameed SM, Yanchar NL, Stelfox HT, Simons R, et al. Mortality in Canadian trauma systems: a multicenter cohort study. Ann Surg. 2017 Jan;265(1):212-17. 
8. McKee JL, Roberts DJ, van Wijngaarden-Stephens MH, Vis C, Gao H, Belton KL, et al. The right treatment at the right time in the right place: a population-based, before-and-after study of outcomes associated with implementation of an all-inclusive trauma system in a large Canadian province. Ann Surg. 2015 Mar;261(3):558-64.

9. Moore L, Turgeon AF, Lauzier F, Émond M, Berthelot S, Clément J, et al. Evolution of patient outcomes over 14 years in a mature, inclusive Canadian trauma system. World J Surg. 2015 Jun;39(6):1397405.

10. MacKenzie EJ, Rivara FP, Jurkovich GJ, Nathens AB, Frey KP, Egleston BL, et al. A national evaluation of the effect of trauma-center care on mortality. N Engl J Med. 2006 Jan;26(4):366-78. 354(.

11. MacKenzie EJ, Weir S, Rivara FP, Jurkovich GJ, Nathens AB, Wang W, et al. The value of trauma center care. J Trauma. 2010 Jul;69(1):1-10.

12. Mackenzie EJ, Rivara FP, Jurkovich GJ, Nathens AB, Frey KP, Egleston BL, et al. The national study on costs and outcomes of trauma. J Ttrauma. 2007 Dec;63(6 Suppl):54-67. discussion S81-6.

13. World Health Organization. WHO global alliance for care of the injured. Available at: https://www.who.int/emergencycare/gaci/gaci_flyer_web.pdf?ua=1. WHO Press. Geneva, Switzerland. Accessed December 1, 2020.

14. World Health Organization. Guidelines for essential trauma care. Geneva: WHO Press; 2004.

15. American College of Surgeons Committee on Trauma. Regional trauma systems: optimal elements, integration, and assessment. Systems consultation guide. Chicago: American College of Surgeons; 2008.

16. American College of Surgeons Committee on Trauma. Resources for Optimal Care of the Injured Patient. Chicago: American College of Surgeons; 2014.

17. Moore L, Champion H, Tardif PA, Kuimi BL, O'Reilly G, Leppaniemi A, et al. Impact of trauma system structure on injury outcomes: a systematic review and meta-Analysis. World J Surg. 2018 May;42(5):1327-39.

18. National Emergency Medical Center. Emergency Medical Statistics Annual Report. 2017. Available at: https://www.e-gen.or.kr/nemc/statistics_annual_report.do?brdclscd=01. National Emergency Medical Center. Seoul, Republic of Korea. Accessed December 1, 2020.

19. Jung KY, Kim JS, Kim Y. Problems in trauma care and preventable deaths. J Korean Soc Emerg Med. 2001 Mar;12(1):45-56.

20. Kim Y, Jung KY, Cho KH, Kim H, Ahn HC, Oh SH, et al. Preventable trauma deaths rates and management errors in emergency medical system in Korea. J Korean Soc Emerg Med. 2006 Oct;17(5):385-94.

21. Kim H, Jung KY, Kim SP, Noh H, Jang HY, Yoon HD, et al. Changes in preventable death rates and traumatic care systems in Korea. J Korean Soc Emerg Med. 2012 Apr;23(2):189-97.

22. Ministry of Health and Welfare. Republic of Korea. Work Plan 2013-2020 in Ministry of Health and Welfare. Available at. 
23. http://www.mohw.go.kr/react/policy/policy_bunissPlan_Is.jsp?PAR_MENU_ID=06\&MENU_ID=0650. Ministry of Health and Welfare. Seoul, Republic of Korea. Accessed December 1, 2020.

24. National Law Information System. Emergency Medical Service Act. Available at: https://www.law.go.kr/LSW//IsInfoP.do? IsiSeq=206719\&chrClsCd=010203\&urlMode=engLsInfoR\&viewCls=engLsInfoR\#0000. Korea Ministry of Government Legislation. Seoul, Republic of Korea. Accessed December 1, 2020.

25. HD Y. Background and progress of regional trauma center development. J Korean Med Assoc. 2016 Dec;59(12):919-22.

26. Maier RV, Rhodes M. Trauma performance improvement. In: Rivara FP, Cummings P, Koepsell TD, Grossman DC, Maier RV, editors. Injury control: a guide to research and program evaluation. New York: Cambridge University Press; 2001. pp. 236-49.

27. Trunkey DD. Invited commentary: panel reviews of trauma mortality. J Trauma. 1999 Sep;47(3 Suppl):44-5.

28. MacKenzie EJ, Steinwachs DM, Bone LR, Floccare DJ, Ramzy Al. Inter-rater reliability of preventable death judgments. The Preventable Death Study Group. J Trauma. 1992 Aug;33(2):292-302. discussion 302-3.

29. Carr BG, Bowman AJ, Wolff CS, Mullen MT, Holena DN, Branas CC, et al. Disparities in access to trauma care in the United States: a population-based analysis. Injury. Feb;48(2):332-38.

30. Hu W, Dong Q, Dong C, Yang J, Huang B. Access to trauma centers for road crashes in the United States. J Saf Res. 2018 Jun;65:21-7.

31. Wei R, Clay Mann N, Dai M, Hsia RY. Injury-based geographic access to trauma centers. Acad Emerg Med. 2019 Feb;26(2):192-204.

32. Dodson BK, Braswell M, David AP, Young JS, Riccio LM, Kim Y, et al. Adult and elderly population access to trauma centers: an ecological analysis evaluating the relationship between injury-related mortality and geographic proximity in the United States in 2010. J Public Health. 2018 Dec 1;40(4):848 - 57.

33. Brown JB, Rosengart MR, Billiar TR, Peitzman AB, Sperry JL. Geographic distribution of trauma centers and injury-related mortality in the United States. J Trauma Acute Care Surg. 2016 Jan;80(1):42-9. discussion 49-50.

\section{Figures}



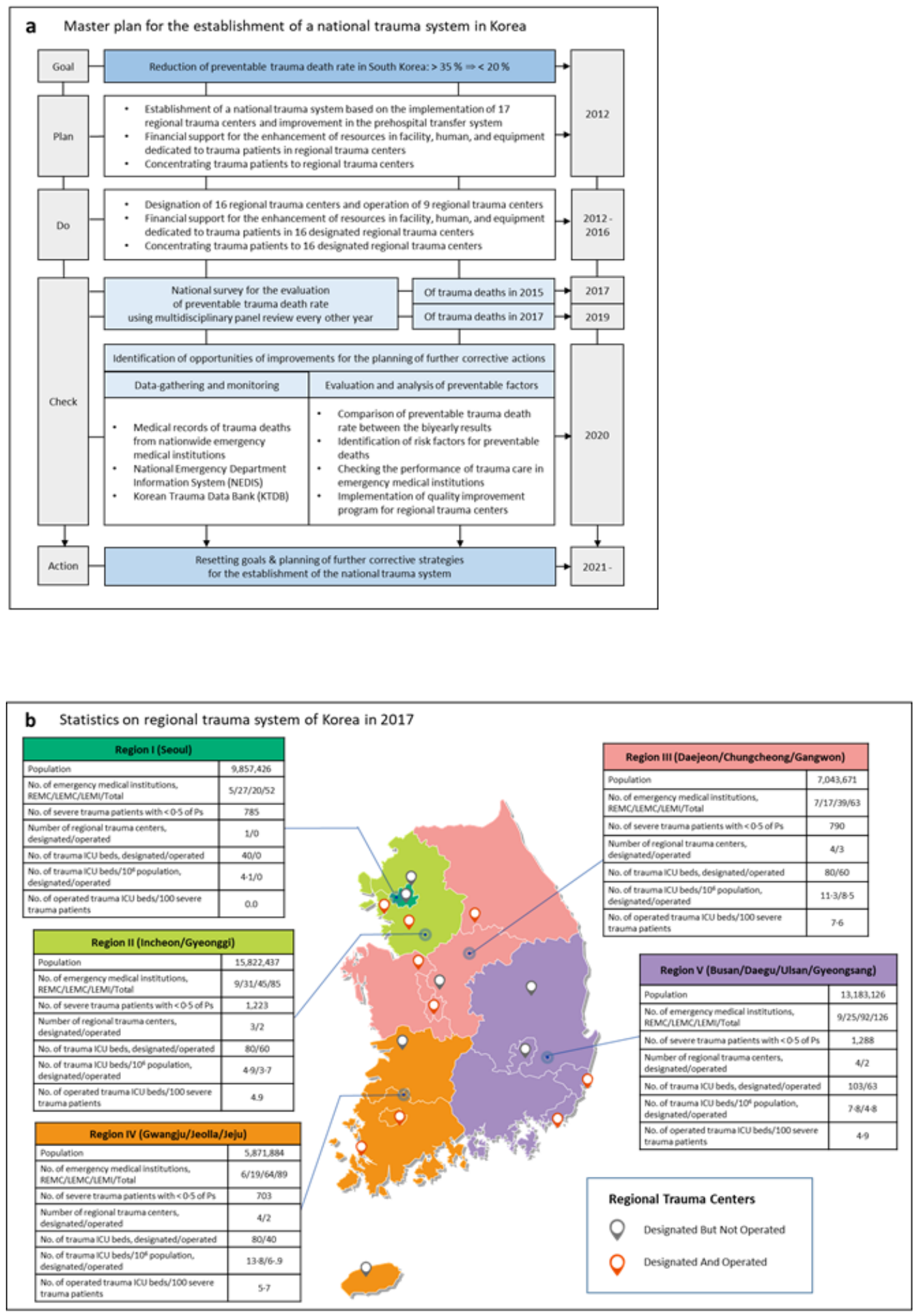

Figure 1

Master plan for the establishment of a national trauma system in South Korea (a) shows the master plan for the establishment of a national trauma system in South Korea. The South Korean government and medical society created the master plan in 2012. It was based on the implementation of regional trauma centers and improvement in the prehospital transfer system for transferring the majority of severe trauma patients to trauma centers. (b) shows that 16 regional trauma centers were designated and nine regional 
trauma centers were officially operational by 2017 after a preparation period of $1-3$ years from 2012 to 2016. It also shows the number of trauma intensive care unit beds per population and severe trauma patients in 2017 according to the five regions (divided in consideration of the population and the administrative district classification in South Korea). No, number; REMC, Regional Emergency Medical Center; LEMC, Local Emergency Medical Center; LEMI, Local Emergency Medical Institution; ICU, intensive care unit. Note: The designations employed and the presentation of the material on this map do not imply the expression of any opinion whatsoever on the part of Research Square concerning the legal status of any country, territory, city or area or of its authorities, or concerning the delimitation of its frontiers or boundaries. This map has been provided by the authors. 
a Flow chart for the comparative analysis of the preventable trauma death rate between 2015 and 2017

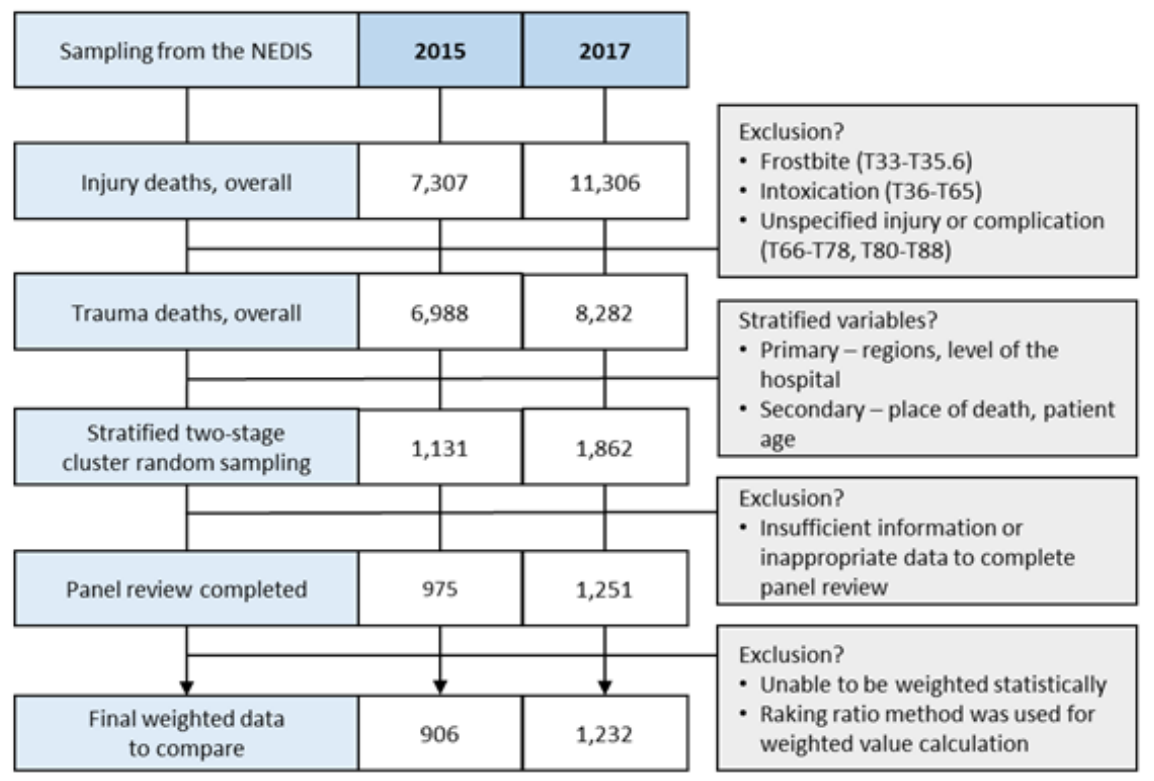

b Flow chart for the comparative analysis of transfer patterns, performance, and outcomes in emergency medical institutions and regional trauma centers

\begin{tabular}{|c|c|c|c|}
\hline \multicolumn{2}{|c|}{$\begin{array}{l}\text { Of the trauma patients who visited } \\
\text { emergency medical institutions }\end{array}$} & 2015 & 2017 \\
\hline \multirow{2}{*}{$\begin{array}{l}\text { ICISS } \\
\text { model }\end{array}$} & $\begin{array}{l}\text { Data available at RTCs, } \\
\text { REMCs, LEMCs, \& LEMIs }\end{array}$ & $1,790,165$ & $1,914,731$ \\
\hline & $\begin{array}{l}\text { Severe trauma patients } \\
\text { with } P_{s}<0.5\end{array}$ & 4,288 & 4,789 \\
\hline \multirow{2}{*}{$\begin{array}{l}\text { Extended } \\
\text { ICISS } \\
\text { model }\end{array}$} & $\begin{array}{l}\text { Data available at RTCs, } \\
\text { REMCs, \& LEMCS }\end{array}$ & 47,806 & 55,057 \\
\hline & $\begin{array}{l}\text { Severe trauma patients } \\
\text { with } \mathrm{PS}_{\mathrm{S}}<0.75\end{array}$ & 3,306 & 3,891 \\
\hline \multirow{2}{*}{$\begin{array}{l}\text { TRISS } \\
\text { model }\end{array}$} & $\begin{array}{l}\text { Data available } \\
\text { at RTCs }\end{array}$ & 4,255 & 6,023 \\
\hline & $\begin{array}{c}\text { Severe trauma patients } \\
\text { with } P_{S}<0.75\end{array}$ & 744 & 1,120 \\
\hline \multicolumn{4}{|l|}{$\downarrow$} \\
\hline \multicolumn{4}{|c|}{$\begin{array}{l}\text { Comparison of transfer patterns, performance, } \& \text { outcomes } \\
\text { at emergency medical institutions and regional trauma centers }\end{array}$} \\
\hline
\end{tabular}

\section{Figure 2}

A flow chart of the study design (a) is a flow chart for the comparative analysis of the preventable trauma death rate via a multi-panel review; (b) is a flow chart for the analysis of the changes in performance, including the transfer patterns of trauma patients and the outcomes of trauma care in the emergency medical system in South Korea. RTC, Regional Trauma Center; REMC, Regional Emergency Medical Center; LEMC, Local Emergency Medical Center; LEMI, Local Emergency Medical Institution; ICU, intensive 
care unit; NEDIS, National Emergency Department Information System; ICISS, International Classification of Disease Injury Severity Score; Ps, probability of survival; TRISS Trauma and Injury Severity Score.
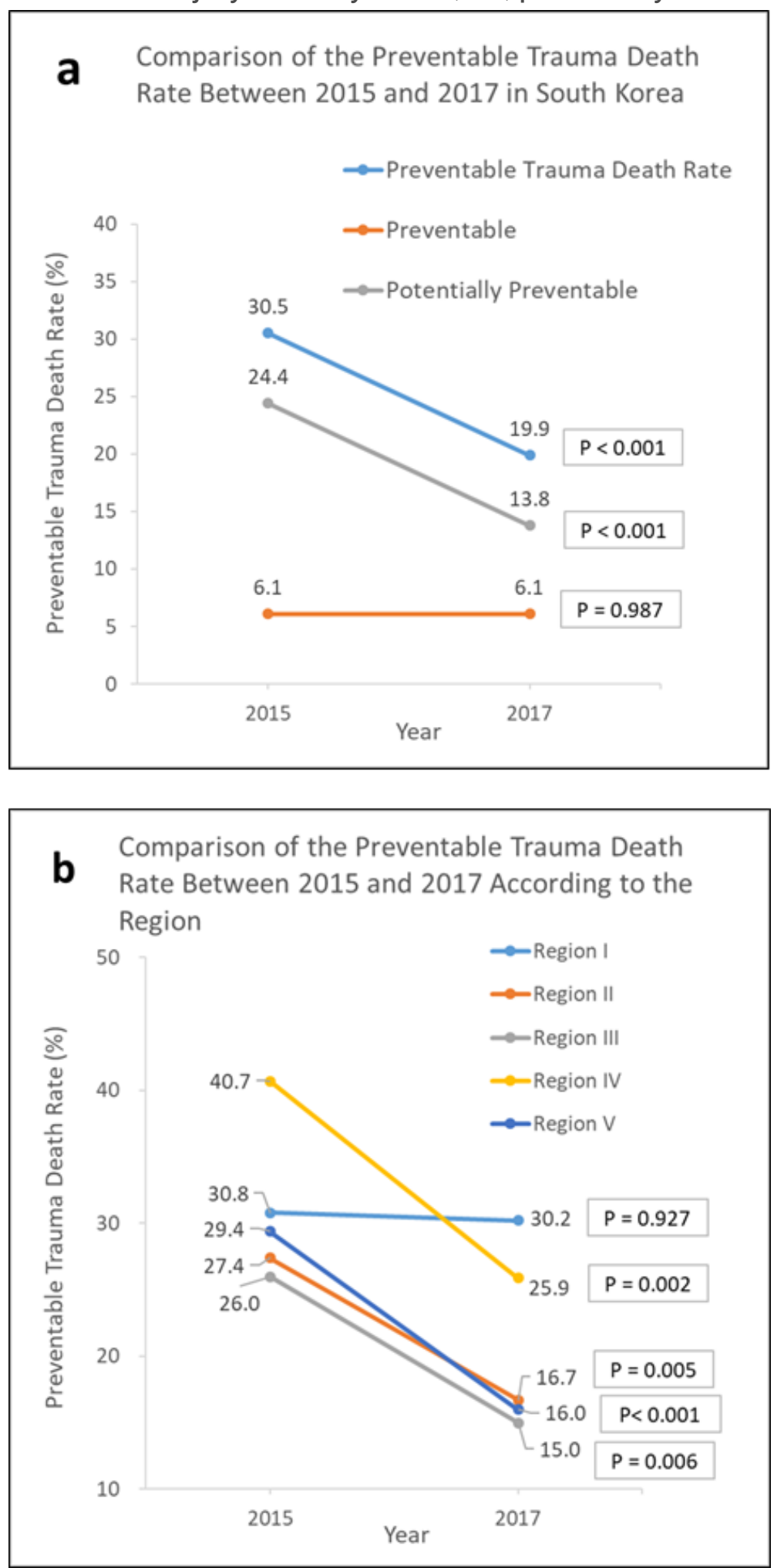

\section{Figure 3}

Comparison of the preventable trauma death rates between 2015 and 2017 (a) and (b) show the results of the comparison of the preventable trauma death rates according to a multi-panel review (between 2015 and 2017). 


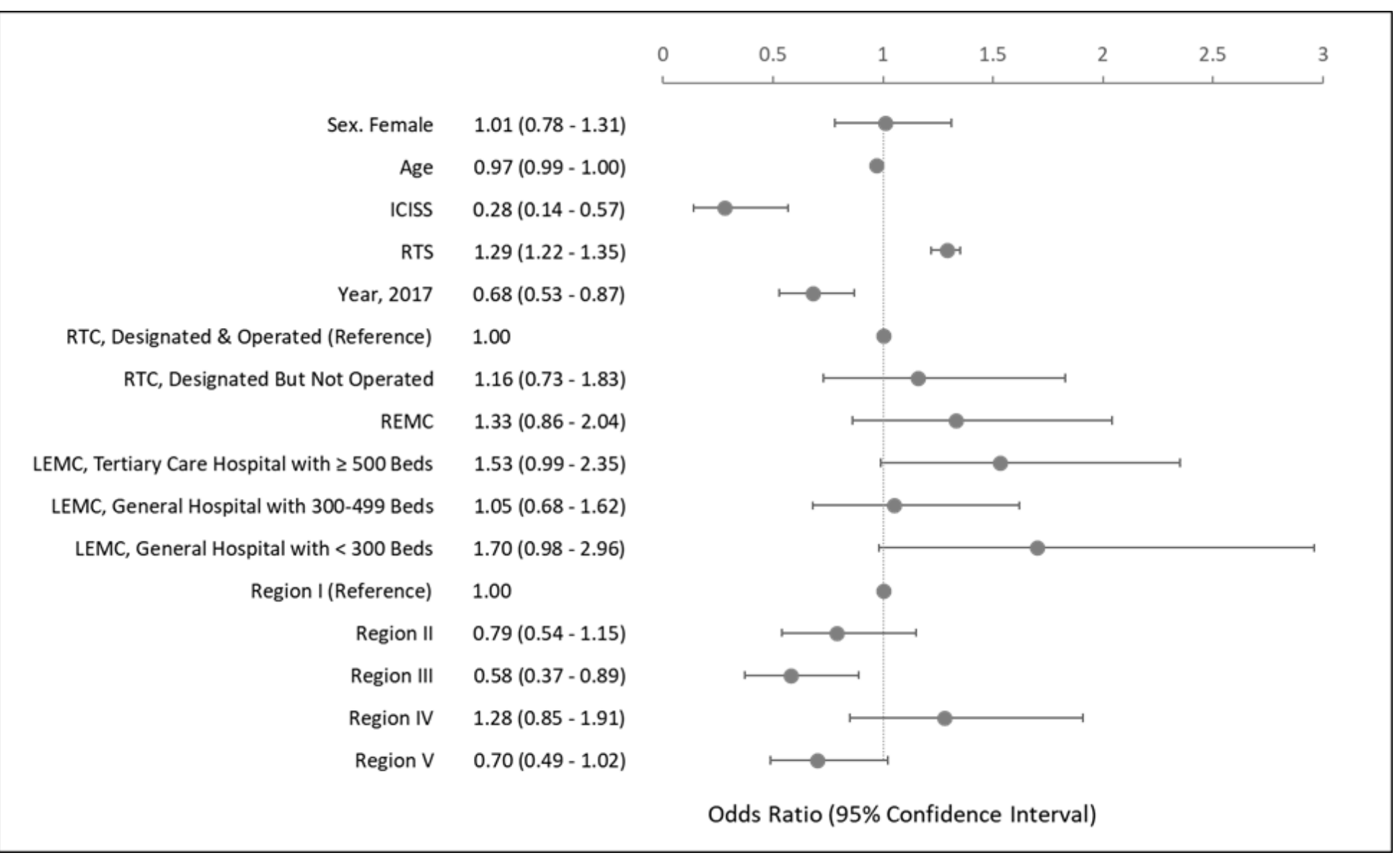

Figure 4

Multivariate analysis of risk factors for preventable trauma deaths Baseline characteristics were compared between two groups using the chi-square or Fisher's exact tests. Logistic regression was used to explain the relationship between preventable trauma deaths and influencing factors. We confirmed that the goodness of fit for logistic regression was satisfactory using the Hosmer-Lemeshow test. Two-sided $P$ values of 0.05 or less were considered to indicate statistical significance. The likelihood of preventable trauma death according to related factors was expressed as odds ratios and $95 \%$ confidence intervals relative to the reference value. ICISS, International Classification of Disease Injury Severity Score; RTS, Revised Trauma Score; RTC, Regional Trauma Center; REMC, Regional Emergency Medical Center; LEMC, Local Emergency Medical Center. 

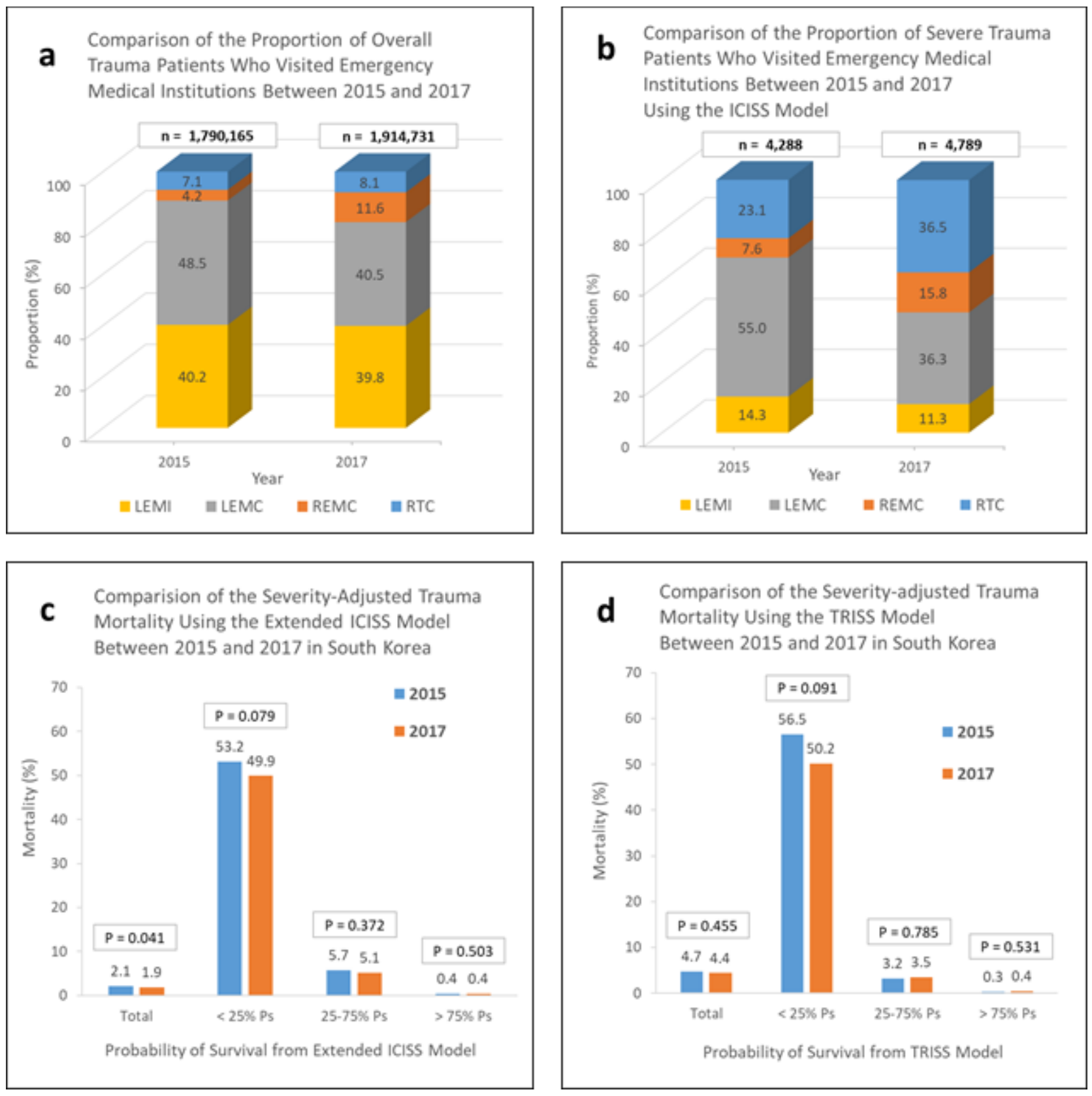

\section{Figure 5}

Changes in performance and outcomes of trauma patients between 2015 and 2017 (a) and (b) are based on the ICISS model targeted to all emergency medical institutions in South Korea. (c) shows the results of the severity-adjusted trauma mortality model using an extended ICISS model targeted for emergency medical institutions other than LEMIs. (d) is a TRISS model resulting from data registered by RTCs. RTC, Regional Trauma Center; REMC, Regional Emergency Medical Center; LEMC, Local Emergency Medical Center; LEMI, Local Emergency Medical Institution; ICISS, International Classification of Disease Injury Severity Score; TRISS, Trauma and Injury Severity Score; Ps, probability of survival.

\section{Supplementary Files}


This is a list of supplementary files associated with this preprint. Click to download.

- Additionalfile1.docx

- Additionalfile2.docx

- Additionalfile3.docx

- Additionalfile4.docx

- Additionalfile5.docx 